\title{
Predictors of Time-to-Contraceptive Use from Resumption of Sexual Intercourse after Birth among Women in Uganda
}

\author{
Robert Wamala, ${ }^{1}$ Allen Kabagenyi, ${ }^{2}$ and Simon Kasasa ${ }^{3}$ \\ ${ }^{1}$ Department of Planning and Applied Statistics, College of Business and Management Sciences, Makerere University, P.O. Box 7062, \\ Kampala, Uganda \\ ${ }^{2}$ Department of Population Studies, College of Business and Management Sciences, Makerere University, P.O. Box 7062, \\ Kampala, Uganda \\ ${ }^{3}$ Department Epidemiology and Biostatistics, College of Health Sciences, Makerere University, P.O. Box 7062, Kampala, Uganda
}

Correspondence should be addressed to Allen Kabagenyi; allenka79@yahoo.com

Received 26 September 2016; Revised 24 December 2016; Accepted 29 January 2017; Published 28 February 2017

Academic Editor: Oliver Duke-Williams

Copyright (C) 2017 Robert Wamala et al. This is an open access article distributed under the Creative Commons Attribution License, which permits unrestricted use, distribution, and reproduction in any medium, provided the original work is properly cited.

Globally, there is extant literature on patterns and dynamics of postpartum contraceptive use with hardly any evidence examining time-to-contraceptive use from resumption of sexual intercourse after birth among women in Uganda. Methods. The analysis was based on data from 2011 Uganda Demographic and Health Survey on a sample of 2983 married women with a birth in the past three years preceding the survey and had resumed sexual intercourse. A time-to-contraceptive use was adopted in the analysis using life tables based on the Kaplan-Meier estimates, while the Log-Rank Chi-square tests assessed the variables to be included in regression analysis. Cox-Proportional Hazard regression was run to identify the predictors of time-to-contraceptive use among postpartum women in Uganda. Sampling weights were applied in the analysis to ensure representativeness. Results. The median time-tocontraceptive use was 19 months (range 0-24). Time to adoption of modern contraceptive use was significantly longer among women with no formal education, residing in northern region, who (HR $=0.56, \mathrm{CI}: 0.40-0.78)$ had delivered at home/traditional birth attendant ( $\mathrm{HR}=0.75, \mathrm{CI}: 0.60-0.93)$, had 1-3 antenatal care visits ( $\mathrm{HR}=0.83, \mathrm{CI}: 0.70-0.98)$, and were in poorest wealth quintile. Conclusions. Measures for enhancing modern contraceptive use during and after the postpartum period should focus on (i) addressing hindrances in accessing family planning, particularly among poor and noneducated women; (ii) integration of family planning service delivery into routine ANC through counseling; and (iii) promoting deliveries in health facilities.

\section{Background}

A considerable proportion of women especially in the developing countries engage in sexual relationships after childbirth without using any contraception [1]. In some instances, resumption of sexual intercourse occurs earlier than the six-week period of postpartum abstinence recommended by health workers $[2,3]$. This has been partly attributed to the existing taboos in many sub-Saharan Africa countries. Worth noting is the fact that abstinence following a birth is widely practiced in most communities of the world, yet with varying and/or unpredictable durations $[4,5]$. A recent study among postpartum women in Nairobi revealed that women resume sexual activity well before their menstruation [6]. Use of contraceptives, however, is delayed in most instances. A study of postpartum women in 17 developing countries showed that only women who had resumed menstruation used family planning [3]. This evidence demonstrates that these women are at a higher risk of unplanned or unwanted pregnancies compared with their counterparts who use contraception before resumption of menstruation. Breastfeeding as an alternative to contraceptive use would not offer some of these women protection against unwanted pregnancies due to varying levels and intensity of breastfeeding [4, 7-10]. Therefore, it is debatable whether breastfeeding can substitute for the use of modern family planning methods during the postpartum period.

The World Health Organization (WHO) reports a global increase in access to and use of modern contraception in the recent past. However, in most developing countries, 
levels of contraceptive use have remained low. This has been attributed, among other factors, to poor health infrastructure and transportation facilities that hinder access to family planning services [11-13]. The situation is worsened by the high level of unmet need for family planning in these countries [14]. Studies further reveal that the preferred longlasting methods of family planning are not always readily available in these countries $[15,16]$. Particularly, women in the postpartum period are regarded as one of the most vulnerable groups of fecund and sexually active women who do not want to have another pregnancy but are not using any method of contraception. In light of these shortfalls, particularly among the vulnerable groups, the high fertility rates of women in these countries should not be surprising. This has contributed to high levels of maternal mortality rates in most sub-Saharan African countries [17]. For example, Uganda's maternal mortality rate of 438 maternal deaths per 1,000 births [18] does not compare favorably with the global estimate of 287 maternal deaths per 1,000 births or the Millennium Development Goal (MDG) target of 230 deaths per 1,000 births by 2015 [19].

With the low level of contraceptive uptake (any method), estimated at $30 \%$ [18], it is questionable that the country's maternal mortality situation will improve significantly in the near future. In affirming the low level of contraceptive use, Andi et al. [20], citing the 2011 Uganda Demographic and Health Survey (UDHS) [18], demonstrate that the country's contraceptive prevalence is one of the lowest among countries in the East African community. The low uptake leads to an increase in the number of unwanted pregnancies, which are usually characterized by short birth intervals. The fact that the country's level of unmet need for family planning, estimated at $34 \%$, is the highest in Eastern Africa [18] worsens further the situation of unwanted pregnancies. In addition, health consequences of short birth intervals include but are not limited to neonatal and infant mortality, low birth weight, and maternal anemia due to postpartum hemorrhage [21, 22]. Therefore, it is not a matter of debate whether or not use of family planning needs to be promoted among women in the country. The contentious issue, however, is the timing for the initiation of contraception following a birth, for which to date there is limited evidence.

The subject of contraceptive use is not new in the literature. Recent studies provide insights into factors that determine contraceptive use among (i) women in the postpartum period $[3,6,23,24]$, (ii) sexually active women in the reproductive age $[20,25,26]$, and (iii) sexually active males [27]. However, studies are limited in providing an understanding of the factors among women particularly after resumption of sexual intercourse following a birth. Subsequently, the issue of time-to-contraceptive use after resumption of sexual intercourse from birth has been underinvestigated. To this end, it is questionable whether the factors influencing contraceptive use also hold true for the period after resumption of sexual intercourse following birth. Therefore, this paper attempts to provide an understanding of factors associated with timing of contraception after resumption of sexual intercourse following a birth.
Theoretical Grounding. The timing of contraception after birth is evaluated in this study based on a series of postpartum behaviors and/or events including breastfeeding, postpartum amenorrhea, and abstinence. Usually, these events do not follow a sequential pattern; initiation of contraception can happen any time after birth depending on, among other factors, a mother's postpartum situation and choice of method to be adopted. For example, initiation can precede resumption of sexual intercourse where a mother adopts contraception immediately after birth. Likewise, adoption of contraception can precede resumption of menses or weaning.

Similar to contraception, breastfeeding has an impact the timing of a subsequent birth; longer durations of breastfeeding are associated with increased birth intervals. A debatable aspect, however, is whether breastfeeding could be adopted as a substitute for contraceptive use. This is mainly on account of varying intensities of breastfeeding among women in various communities. In affirming the relevance of breastfeeding in child spacing, the expert group at the 1988 Bellagio meeting determined that the maximum birth spacing effect of breastfeeding is achieved when a mother fully or nearly fully breastfeeds and remains amenorrheic. Lactational amenorrhea (LAM) is highly recommended given the accrued benefits to the baby and only a $2 \%$ risk of pregnancy to women $[18,28]$.

Sexual abstinence can also influence the risk of pregnancy in the postpartum period. In a scenario where the duration of abstinence goes beyond that of postpartum amenorrhea, postpartum sexual abstinence provides contraceptive benefits. Nevertheless, the duration of postpartum sexual abstinence varies across communities $[4,5]$.

Contraceptive use, breastfeeding, and resumption of sexual intercourse may be mediated by psychological factors and by the socioeconomic and demographic characteristics of women. Figure 1 presents a diagrammatic representation of these factors and how they relate to the time-to-contraceptive use after resumption of sexual intercourse following birth.

The predisposing factors identified in the study by socioeconomic and demographic characteristics of individuals are suggested to impact directly on contraceptive use. There exists a wide range of literature in Uganda and elsewhere in support of the impact of these factors. The debatable aspect, however, is whether or not the literature is supported among contraceptive users in the period from resumption of sexual intercourse after birth.

With regard to socioeconomic factors, contraceptive use has been associated in the literature with education level [18, $20,25,29]$, wealth status [30], residence [18, 20, 31], religion [31-33], and working status. The consensus with regard to residence is that the level of contraceptive use is higher among urban residents compared with rural residents. In a recent study of trends and patterns of modern contraceptive use among women in Uganda, Andi et al. [20] affirm that shortfalls in accessibility, availability of method choice, and affordability are the major causes of the low level of family planning use in the rural areas. Given that the northern region of the country is predominantly rural, it is not surprising that the region has lower contraceptive prevalence 


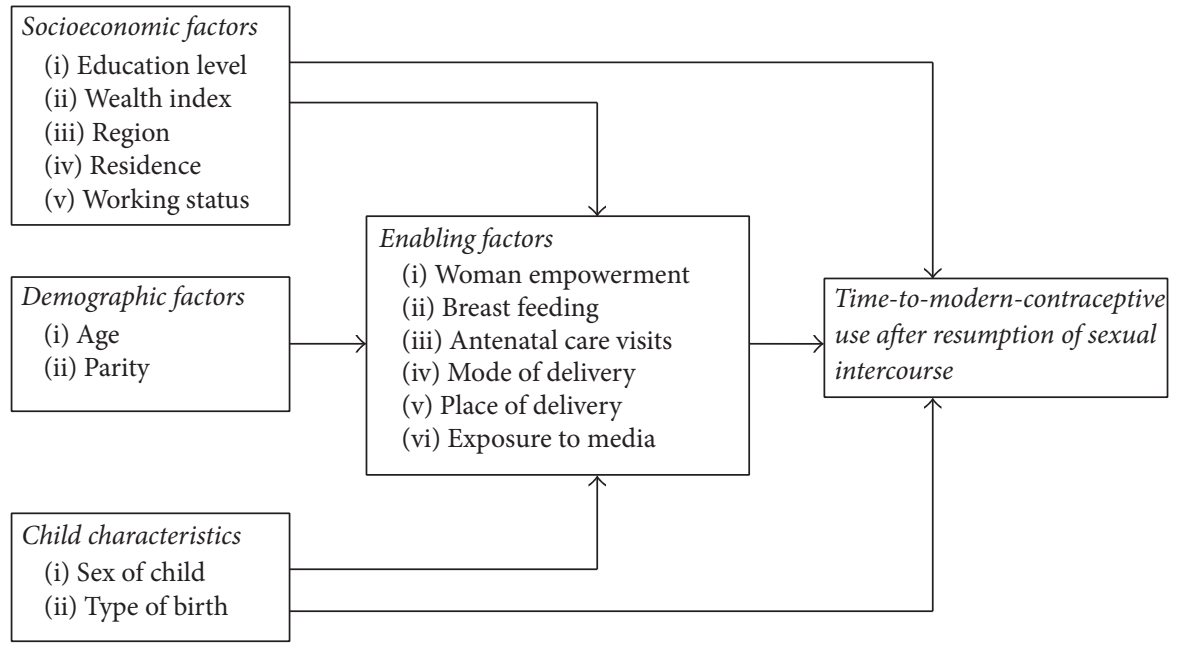

FIGURE 1: Conceptualization of factors associated with time-to-contraceptive use from resumption of sexual intercourse after birth.

compared with the central region, which is predominantly urban.

Educated women are regarded as having higher odds of modern contraceptive use compared with the noneducated ones $[25,29,34]$. The contentious issues, however, are as follows: (i) whether contraceptive use increases with education level and (ii) the minimum level of education is associated with increased odds of contraceptive use. In a study of women in six sub-Saharan African countries, secondary or higher education was associated with modern contraceptive use [25]. However, this may not be the case in countries elsewhere due to variations in characteristics of individuals and their communities. Certainly, household wealth plays an important role in promoting contraceptive use because of the cost implications associated with its uptake $[20,35]$. In their extensive review of the literature, Andi et al. [20] reveal that other costs associated with the services (e.g., transport) would hinder people from seeking family planning services even if formal fees on the service were nonexistent or low. Contraceptive use is reported to be twice as likely among the wealthiest women compared with the poorest women [30].

The literature on family planning use shows that contraceptive use assumes an inverse U-shape relationship with women's age. Contraceptive use increases up to about the early 30 s and declines at older ages $[8,25]$. Pertaining to parity, contraceptive use is more likely among women with a higher number of surviving children as noted in Uganda [20].

Discussion of the role of enabling factors in enhancing the use of family planning goes back to the early 1990s. In a model of health care utilization, Andersen argues that the presence or absence of these factors would promote or hinder use of health care [36]. Among the reasons why women who do not want to get pregnant do not use contraception are opposition from partners and poor access to and quality of family planning services [37, 38], while others use of contraceptive use is predetermined by partners acceptability [24].

\section{Methods}

2.1. Data Source. The study was based on data from the 2011 Uganda Demographic and Health Survey (UDHS) (Uganda Bureau of Statistics (UBOS) and ICF International, 2012). This cross-sectional survey follows previous DHS surveys in 2006, 2000, 1995 and 1988. The survey compiled data using questionnaires for households, women and men. These data are part of multinational demographic and health surveys program conducted in over 100 countries and supported by USAID funded project under MEASUREDHS. The programs aims at protecting survey participants by obtaining informed consent prior to data collection and ensuring privacy and maintaining anonymity.

2.2. Selection Criteria. This study was based on data from the Woman's Questionnaire, which was administered to all women aged 15-49 in the selected households. A nationally representative sample of 8,624 women was obtained based on a two-stage cluster sampling. The first and second stages involved the selection of the clusters and households in each cluster, respectively. Further, stratification by rural-urban areas was taken into account. The sample excluded (i) women with no births in the past three years preceding the survey $(n=4,632)$; (ii) women who were not in a marital union $(n=$ $582)$ and those whose last birth was not within a union $(n=$ 63); and (iii) women who had not resumed sexual intercourse by the time of the survey $(n=434)$. Thus, contraceptive use was investigated using a sample of married women with a birth in the past three years preceding the survey who had resumed sexual intercourse $(n=2,983)$. The study's focus on women in union was based on the indicators of assessing family planning, including contraceptive prevalence and unmet need. The study focused on women who had initiated sexual intercourse during the postpartum period because they are at risk of getting pregnant. Postpartum abstinence is not recorded in the calendar data. Thus, we linked the calendar data to the individual woman file. The study therefore 


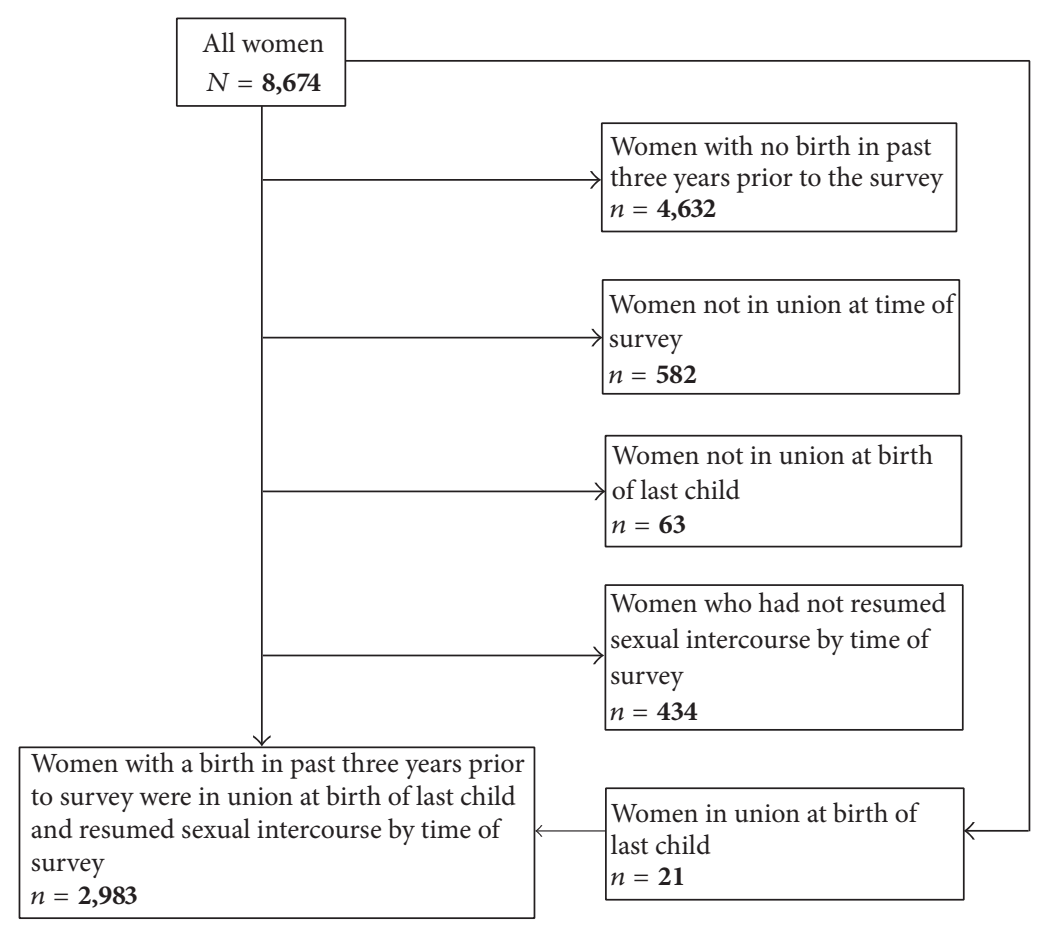

FIGURE 2: Derivation of weighted sample adopted in the investigations and variables and their measurements.

acknowledges measurement errors that exist in both sources of data.

Figure 2 illustrates how the weighted sample used in the study was derived.

2.3. Study Variables. The study assessed time-to-contraceptive use, estimated in months, by the period from resumption of sexual intercourse following a birth to the time when a woman used modern contraception. The period is recorded using a nonnegative integer value between 0 and 24, where the value zero denotes women who initiated contraception either before or at the same time as resumption of sexual intercourse. The time-to-contraceptive use was compiled from contraceptive calendar data containing information about births, pregnancies, and contraceptive use in the five years preceding the survey. The calendar provides retrospective month-by-month experience of each surveyed woman with regard to aspects of reproductive health [39]. Reasons for discontinuation of each contraceptive method used also are included in the full calendar.

In this study, postpartum contraceptive use was assessed based on the two-year minimum period recommended by WHO before stopping contraception to become pregnant [40]. Nevertheless, some women were not using modern contraception (any method) at the time of the study. A status variable, denoted by a value of zero (0), was generated to represent these women. Otherwise, the women were represented by a status value of one.

As earlier indicated, the independent variables considered in the investigations were (i) demographic characteristics of women, namely, age and marital status; (ii) socioeconomic characteristics, namely, education level, wealth status, region, residence, and working status; (iii) child characteristics, namely, sex, birth order, and type of birth (single or multiple); and (iv) enabling factors, namely, women's empowerment, mode of delivery (normal or Caesarean birth), place of delivery (public, government, and other), number of antenatal care (ANC) visits, breastfeeding, and exposure to media.

Worth noting are the generated variables, namely, empowerment and exposure to media. An index of women's empowerment was generated based on the survey data on decision-making about health, household purchases, visits to family or relatives, and woman's earnings. Each of these aspects was recorded using a binary outcome that is whether or not a woman was involved in decision-making, denoted by codes one and zero (0), respectively. Using these, the index was generated using factor analysis and was later divided into three levels: high, medium, and low. Likewise, exposure to media was evaluated using a binary outcome, whether or not a woman was exposed regularly (at least once a week) to any type of media, namely, newspapers, radio, or television. With regard to region, the variable was converted from the 10 conventional DHS classifications to four groups, namely, Central (Kampala, Central 1 and Central 2), East (East Central and Eastern), North (North, Karamoja, and West Nile), and West (Western and South West).

2.4. Data Analysis. The analysis was made using STATA 13.1 at three stages: first, a descriptive summary of women by their socioeconomic and sociodemographic characteristics was made, using frequency distributions. An assessment of the time-to-contraceptive use from resumption of sexual intercourse after birth was made using life tables based on 
the Kaplan-Meier estimate. Second, differentials in the timeto-contraceptive use were investigated by socioeconomic and demographic characteristics of women as well as child and enabling factors, using the Log-Rank Chi-square test. The purpose of the assessment was to select variables for further analysis at the subsequent stage. All variables with a relatively high probability value $(p>0.25)$ were excluded from the analysis at the subsequent stage unless otherwise indicated. Third, the predictors of the time-to-contraceptive use were investigated using a Cox-Proportional Hazard (Cox- $\mathrm{PH}$ ) regression. The time-to-event approach adopted in the study is able to deal with women irrespective of whether or not they had used modern contraception by the time of the study. In light of the multistage design adopted in the selection of the respondents, sampling weights were applied in the analysis to ensure representativeness across the country and to correct for nonresponses, stratified by regions and residence [18]. The appropriateness of using the fitted Cox- $\mathrm{PH}$ regression in modeling time-to-contraceptive use was investigated using a link specification test. Further, assessment of multicollinearity was carried out using the Coldiag regression collinearity diagnostic procedure [41]. Using the diagnostic test, based on a matrix of independent variables, a condition number of 30 or higher is associated with collinearity problems. Subsequently, large variance decomposition portions $(50 \%$ or more) between any two or more variables would suggest collinearity problems.

\section{Results}

The subsequent sections present results on characteristics of women, time-to-contraceptive use, and predictors of timeto-contraceptive use. As earlier indicated, the assessment was based on married women who had resumed sexual intercourse after birth.

3.1. Characteristics of Women. Table 1 presents a distribution of the women by their socioeconomic and demographic characteristics as well as enabling factors.

The women assessed in the study were predominantly rural residents $(86 \%)$, with primary $64 \%$ as their highest level of education attained. Forty percent of the women were Catholics, while the rest were Protestants (30\%), Muslims (13\%), Pentecostals (13\%), and other religious affiliations (4\%). With regard to age, the majority of women $(56 \%)$ were in their $20 \mathrm{~s}$, while about one-third (32\%) were in their 30 s, with the rest either below the age of $20(6 \%)$ or age of 40 or older $(6 \%)$. No major variations were noted in the distribution of women with regard to their wealth status. Among regions, the highest proportion of women lived in the South (33\%), followed by Central (27\%), East (28\%), and North (13\%). Nearly eight in every ten women (79\%) reported working.

With regard to the enabling factors, nearly all women (94\%) had normal birth delivery; the highest proportion of women had deliveries in public facilities (45\%) and the lowest proportion in private facilities (14\%), with the rest delivering elsewhere, whether at home or with a traditional
TABLE 1: Distribution by women's characteristics and predisposing factors.

\begin{tabular}{|c|c|c|}
\hline Characteristics & $n=2983$ & Percentage (\%) \\
\hline \multicolumn{3}{|l|}{ Age } \\
\hline $15-19$ & 178 & 6.0 \\
\hline $20-29$ & 1661 & 55.7 \\
\hline $30-39$ & 958 & 32.1 \\
\hline $40-49$ & 186 & 6.2 \\
\hline \multicolumn{3}{|l|}{ Education level } \\
\hline None & 414 & 13.9 \\
\hline Primary & 1905 & 63.9 \\
\hline Secondary & 664 & 22.3 \\
\hline \multicolumn{3}{|l|}{ Residence } \\
\hline Urban & 408 & 13.7 \\
\hline Rural & 2575 & 86.3 \\
\hline \multicolumn{3}{|l|}{ Wealth status } \\
\hline Lowest & 604 & 20.3 \\
\hline Second & 673 & 22.6 \\
\hline Middle & 613 & 20.6 \\
\hline Fourth & 531 & 17.8 \\
\hline Highest & 562 & 18.8 \\
\hline \multicolumn{3}{|l|}{ Religion } \\
\hline Catholic & 1200 & 40.2 \\
\hline Protestant & 892 & 29.9 \\
\hline Muslim & 386 & 12.9 \\
\hline Pentecostal & 398 & 13.4 \\
\hline Other & 107 & 3.6 \\
\hline \multicolumn{3}{|l|}{ Region } \\
\hline Central & 791 & 26.5 \\
\hline East & 825 & 27.7 \\
\hline North & 381 & 12.8 \\
\hline South & 986 & 33.1 \\
\hline \multicolumn{3}{|l|}{ Working status } \\
\hline Not working & 630 & 21.1 \\
\hline Working & 2353 & 78.9 \\
\hline \multicolumn{3}{|l|}{ Type of birth } \\
\hline Normal & 2813 & 94.3 \\
\hline Caesarean & 170 & 5.7 \\
\hline \multicolumn{3}{|l|}{ Place of delivery } \\
\hline Public & 1,342 & 45.0 \\
\hline Private & 424 & 14.2 \\
\hline TBA/Home & 1,217 & 40.8 \\
\hline \multicolumn{3}{|c|}{ Number of ANC visits } \\
\hline None & 163 & 5.5 \\
\hline $1-3$ & 1395 & 46.8 \\
\hline $4++$ & 1425 & 47.8 \\
\hline \multicolumn{3}{|l|}{ Type of birth } \\
\hline Single & 2,924 & 98.0 \\
\hline Multiple & 59 & 2.0 \\
\hline \multicolumn{3}{|l|}{ Sex of child } \\
\hline Male & 1,492 & 50.0 \\
\hline
\end{tabular}


TABle 1: Continued.

\begin{tabular}{lcc}
\hline Characteristics & $n=2983$ & Percentage (\%) \\
\hline Female & 1,491 & 50.0 \\
\hline Breastfeeding & & \\
$\quad$ Not breastfeeding & 1,189 & 39.9 \\
$\quad$ Breastfeeding & 1,794 & 60.1 \\
\hline Birth order & & \\
$\quad$ First & 367 & 12.3 \\
$2-3$ & 939 & 31.5 \\
$4-5$ & 743 & 24.9 \\
6++ & 934 & 31.3 \\
\hline Empowerment & & \\
Low & 1,141 & 38.2 \\
Medium & 1,273 & 42.7 \\
High & 569 & 19.1 \\
\hline Exposure to media & & \\
$\quad$ No exposure & 669 & 77.6 \\
$\quad$ At least one regularly & 2,314 & \\
\hline
\end{tabular}

Note. Estimates are based on weighted scores.

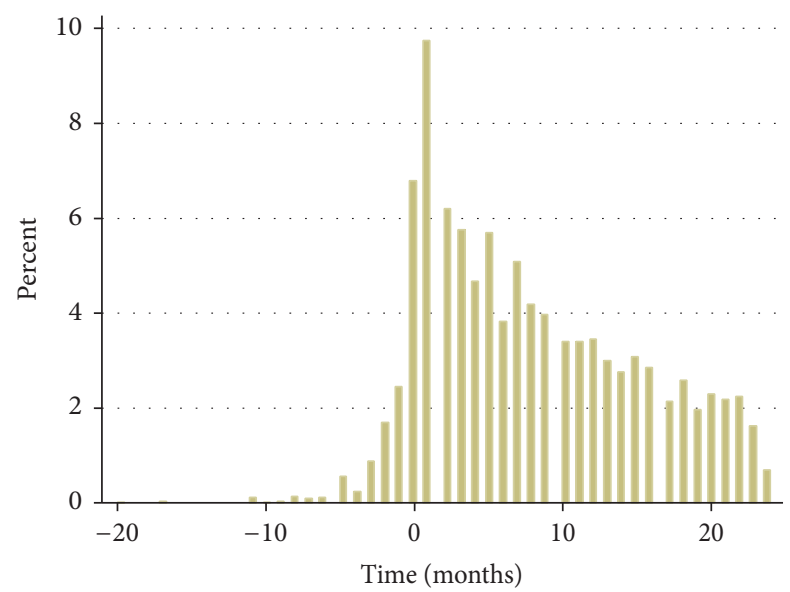

FIGURE 3: Distribution by timing of contraception based on resumption of sexual intercourse.

birth attendant (TBA). Slightly less than a half of the women (48\%) had the recommended number of four or more ANC visits, and $47 \%$ had $1-3$ visits. With regard to breastfeeding, nearly two-thirds of women $(60 \%)$ were breastfeeding at the time of the survey. Nearly eight in every ten women (78\%) were exposed regularly to at least one form of media, comprising newspapers, radio, and television.

Pertaining to child characteristics, Table 1 shows a similar proportion of males and females. By birth order, the highest proportion of children were either second or third born (32\%), followed closely by birth order six or higher (31\%), while $25 \%$ were birth order of $4-5$ and $12 \%$ were firstborn.

3.2. Time-to-Contraceptive Use. A total of 1,072 (36\%) out of the 2,983 women assessed in the study used a modern contraceptive method by the date of interview. Figure 3 presents the distribution of the timing of contraception for women who used modern contraception. The figure shows that women initiated contraception at three stages: (i) before resumption of sexual intercourse, denoted by negative time values ( $n=179)$; (ii) at resumption of sexual intercourse, represented by time zero $(n=135)$; and (iii) after resumption of sexual intercourse, represented by positive time values $(n=$ 758).

Table 2 presents a life table showing the timing of contraceptive use after resumption of sexual intercourse following birth of the most recent child.

Results in Table 2 reveal an upward trend in the proportion of women using contraception after resumption of sexual intercourse following birth. The number using modern contraception before or during the time of resumption of sexual intercourse $(n=314)$ denotes a proportion of $11 \%$. Subsequently, the proportions of women using contraception during the first $(n=466)$, second $(n=532)$ and third month $(n=607)$ after resumption of sexual intercourse following birth are $16 \%, 18 \%$, and $20 \%$, respectively. The median time-to-contraceptive use from resumption of sexual intercourse following birth is about 19 months (range 0-24 months). This estimate is influenced by a relatively large proportion of women $(64 \%)$ who did not use contraception after resumption of sexual intercourse by the time of the study. An attempt to provide an estimate of the central tendency only among women who used modern contraception would provide results biased towards the earlier months.

3.3. Differentials in Time-to-Contraceptive Use. Differentials in time-to-contraceptive use were assessed by socioeconomic and demographic characteristics of women as well as child and enabling factors. As earlier indicated, the purpose of the assessment was to select variables for further analysis at the multivariable stage, that is, variables with a relatively small probability value $(p<0.25)$. Table 3 presents results of the assessment.

With the exception of child characteristics, namely, type of birth and sex of child, Table 3 shows that the rest of the variables assessed were eligible for inclusion at the multivariable stage $(p<0.25)$. However, birth order was excluded from the analysis at the subsequent stage, despite being significantly associated with the odds of contraceptive use, based on the results of the Log-Rank test in Table 3. The exclusion was based on the fact that the variable made only a minimal contribution to the final model when adjusted for all the independent variables studied.

The illustrations in Figures 3-5 provide insights into the nature of associations between selected variables and timing of adoption of modern contraception after resumption of sexual intercourse following a birth.

Figures 3-5 show delayed initiation of modern contraceptive use after resumption of sexual intercourse following a birth among women with no education compared with women with primary or postprimary education. Women who gave birth at home or assisted by a TBA had delayed initiation of modern contraceptive use compared with women delivering in a health facility. Women who attended 1-3 ANC visits had delayed initiation compared with women who 
TABLE 2: Timing of contraceptive use after resumption of sexual intercourse.

\begin{tabular}{|c|c|c|c|c|c|}
\hline Time (months) & Total & $\mathrm{FP}^{\mathrm{a}}$ & Censored & Std. error & Survival \\
\hline 0 & 2983 & 314 & 80 & 0.0565 & 0.8934 \\
\hline 1 & 2589 & 152 & 139 & 0.0464 & 0.8395 \\
\hline 2 & 2298 & 66 & 119 & 0.0436 & 0.8149 \\
\hline 3 & 2114 & 75 & 97 & 0.0409 & 0.7853 \\
\hline 4 & 1942 & 50 & 90 & 0.0394 & 0.7647 \\
\hline 5 & 1802 & 54 & 116 & 0.0381 & 0.7410 \\
\hline 6 & 1632 & 28 & 86 & 0.0375 & 0.7278 \\
\hline 7 & 1518 & 51 & 101 & 0.0365 & 0.7026 \\
\hline 8 & 1367 & 32 & 93 & 0.0360 & 0.6858 \\
\hline 9 & 1242 & 27 & 91 & 0.0357 & 0.6702 \\
\hline 10 & 1123 & 38 & 64 & 0.0354 & 0.6469 \\
\hline 11 & 1022 & 26 & 76 & 0.0352 & 0.6301 \\
\hline 12 & 920 & 24 & 79 & 0.0352 & 0.6129 \\
\hline 13 & 817 & 22 & 68 & 0.0352 & 0.5960 \\
\hline 14 & 728 & 27 & 56 & 0.0354 & 0.5733 \\
\hline 15 & 646 & 27 & 65 & 0.0358 & 0.5483 \\
\hline 16 & 554 & 18 & 67 & 0.0363 & 0.5294 \\
\hline 17 & 468 & 5 & 59 & 0.0365 & 0.5239 \\
\hline 18 & 405 & 12 & 65 & 0.0374 & 0.5064 \\
\hline 19 & 327 & 9 & 50 & 0.0385 & 0.4916 \\
\hline 20 & 269 & 7 & 60 & 0.0400 & 0.4766 \\
\hline 21 & 201 & 8 & 57 & 0.0432 & 0.4545 \\
\hline 22 & 136 & 2 & 64 & 0.0460 & 0.4436 \\
\hline 23 & 69 & 0 & 48 & 0.0460 & 0.4436 \\
\hline 24 & 21 & 0 & 21 & 0.0460 & 0.4436 \\
\hline
\end{tabular}

Note. Zero (0) denotes women who initiated contraception either before or at resumption of sexual intercourse; a denotes use of modern contraception.

TABLE 3: Differentials in time-to-contraceptive use.

\begin{tabular}{lcc}
\hline Independent variables & $\chi^{2}$ & $p$ value \\
\hline Age & 15.70 & 0.0013 \\
Education level & 182.87 & 0.0000 \\
Residence & 111.25 & 0.0000 \\
Wealth status & 191.91 & 0.0000 \\
Religion & 14.52 & 0.0058 \\
Region & 111.79 & 0.0000 \\
Empowerment & 5.56 & 0.0722 \\
Number of ANC visits & 11.85 & 0.0027 \\
Place of delivery & 71.30 & 0.0000 \\
Type of delivery & 13.75 & 0.0002 \\
Working status & 2.60 & 0.1066 \\
Breastfeeding & 3.74 & 0.1539 \\
Exposure to media & 48.18 & 0.0000 \\
Sex of child & 0.69 & 0.4049 \\
Type of birth & 0.00 & 0.9792 \\
Birth order & 49.14 & 0.0000 \\
\hline
\end{tabular}

attended the recommended four or more visits. However, these findings must be verified after adjusting for the rest of the variables at the multivariate analysis stage.
3.4. Predictors of Time-to-Contraceptive Use. Table 4 presents results of unadjusted and adjusted hazards for the odds of contraceptive use by selected socioeconomic and demographic characteristics, as well as enabling factors. The unadjusted hazard ratios denote analysis on each of the independent variables by the timing of contraceptive use. The results provide insights into the changes in the impact of the variables when all variables are controlled for.

3.5. Regression Diagnostics. Table 5 presents results of the link specification test for the Cox-PH model fitted in Table 4. As stated earlier, the assessment evaluates the appropriateness of using the model in the analysis of contraceptive use.

Results of the specification test shows that the model was well specified as predicted by the Hat-statistic $(p<0.05)$. Results of the Hat-square statistic do not reveal, otherwise, the appropriateness of using the fitted model $(p>0.05)$. Particularly, the Hat-square statistic demonstrates that any additional variables do not have much explanatory power. The fact that the proportionality hazard assumption is a specification test demonstrates that the model has chosen an appropriate specification for the covariates. On the other hand, the conditioning number of 14.5 derived from the Coldiag regression collinearity diagnostic test implies no multicollinearity problems with the independent variables adopted in the investigations [41]. 


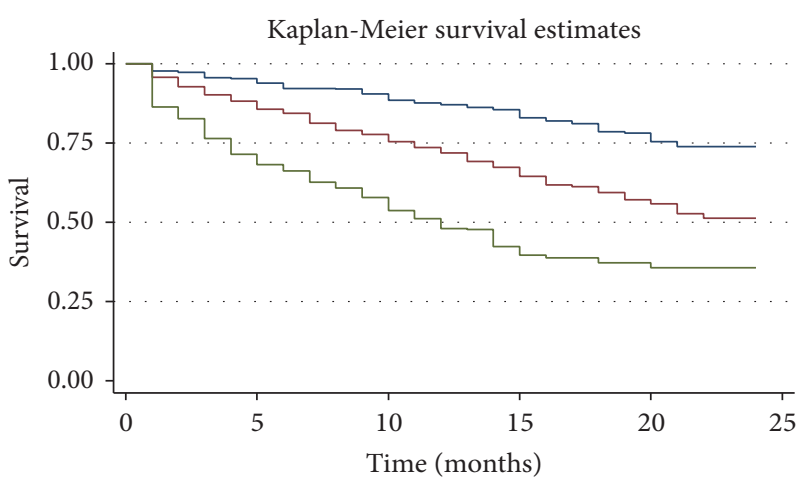

- None
Postprimary

FIGURE 4: Survivorship by education level.
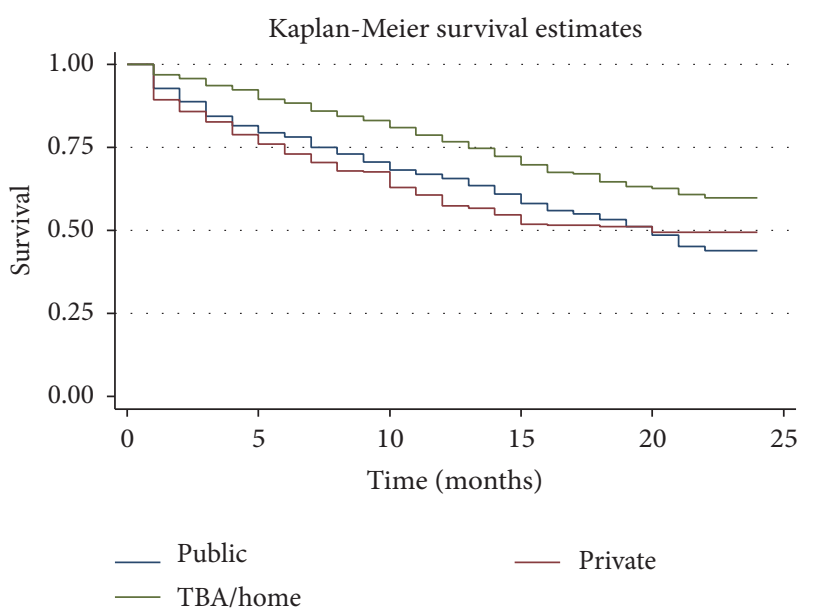

Figure 5: Survivorship by place of delivery.

After adjusting for all the variables adopted in the analysis, the characteristics of women that were associated with the time-to-contraception use after resumption of sexual intercourse were household wealth, region, and education level $(p<0.05)$. The odds of contraceptive use were about $56 \%(\mathrm{HR}=1.56)$ higher for women in the richest wealth quintile compared with the poorest quintile. This implies that women in the richest wealth quintile had a shorter time to adoption of modern contraception compared with those in the poorest quintile. Regarding highest education attained, women with primary $(\mathrm{HR}=1.83)$ and secondary $(\mathrm{HR}=2.66)$ education were associated with higher odds of contraceptive use after resumption of sexual intercourse compared with women with no education. This implies that women with primary and secondary education had a shorter time to adoption of contraception compared with women who had no formal education. A similar pattern was demonstrated by the findings based on the unadjusted ratios.

Women in the northern region of the country had $44 \%$ lower odds of contraceptive use after resumption of sexual intercourse compared with women in the central $(\mathrm{HR}=$ 0.56). In other words, women in the northern region had a longer time to adoption of modern contraception compared with their counterparts in the central region.

After adjusting for all the covariates, the enabling factors that were significantly associated with time-to-contraceptive use after resumption of sexual intercourse were ANC attendance and place of delivery $(p<0.05)$. Delivery with a TBA or at home was associated with $25 \%$ lower odds of contraceptive use after resumption of sexual intercourse compared with deliveries in government health facilities $(\mathrm{HR}=0.75)$. This implies that women who delivered at a government health facility had a shorter time to adoption of modern contraception compared with births at home/TBA. Regarding ANC, women who attended 1-3 visits were associated with lower odds of contraceptive use after resumption of sexual intercourse compared with women who attended the recommended number of four or more visits $(\mathrm{HR}=0.83)$. This implies that women who attended four or more ANC visits had a shorter time-to-contraceptive use compared with those attending 1-3 visits. A similar pattern was demonstrated by the findings based on the unadjusted ratios.

No significant impact on the odds of contraceptive use was noted in the results by the rest of the factors, namely, age, empowerment, exposure to media, type of delivery (whether or not by Caesarean), woman's working status, and breastfeeding $(p>0.05)$.

\section{Discussion}

This study analyzed data from the 2011 UDHS using the contraception calendar to investigate the timing of contraceptive use after resumption of sexual intercourse following a birth. The findings show a low level of modern contraceptive use after resumption of sexual intercourse following a birth. The results regarding the timing of adoption of contraception reveal a delay in the initiation of contraceptive use after resumption of sexual intercourse, which suggests that a considerable proportion of women in Uganda are at a high risk of unwanted or unplanned pregnancies. The issue of unwanted pregnancies is worsened by the country's high level of unmet need for family planning [18]. To this end, it should not be surprising that the country has one of the highest fertility rates in sub-Saharan Africa and elsewhere [42, 43].

The predictors of the time-to-contraceptive use after resumption of sexual intercourse following a birth are identified in the study as household wealth, region, education, number of ANC visits, and place of delivery. Regarding household wealth, the study reveals a shorter time-tocontraceptive use among women in richest quintile compared with the poorest. The findings are in agreement with studies that show higher levels of modern contraceptive use among the wealthiest women $[33,35,44]$. These studies attribute the low level of contraceptive use among poor women mainly to the costs associated with the services. Further, the studies reveal that other costs associated with the services could influence contraceptive use even where fees on the contraception are nonexistent. One could therefore conclude that the delayed initiation of contraception among the poor women is an issue of the costs. To this end, it should not be 
TABLE 4: Multivariable analysis of time-to-contraceptive use after resumption of sexual intercourse.

\begin{tabular}{|c|c|c|}
\hline \multirow{2}{*}{ Characteristics } & \multicolumn{2}{|c|}{ Hazard ratio $(95 \% \mathrm{CI})$} \\
\hline & Unadjusted & Adjusted \\
\hline \multicolumn{3}{|l|}{ Age } \\
\hline $15-19^{\dagger}$ & 1.00 & - \\
\hline $20-29$ & $0.93(0.63-1.46)$ & $0.93(0.63-1.38)$ \\
\hline $30-39$ & $0.80(0.54-1.17)$ & $0.81(0.54-1.20)$ \\
\hline $40-49$ & $0.64(0.37-1.08)$ & $0.77(0.44-1.37)$ \\
\hline \multicolumn{3}{|l|}{ Education level } \\
\hline None $^{\dagger}$ & 1.00 & 1.00 \\
\hline Primary & $2.25(1.57-3.23)^{* *}$ & $1.83(1.25-2.68)^{* *}$ \\
\hline Postprimary & $4.61(3.09-6.89)^{* *}$ & $2.66(1.66-4.26)^{* *}$ \\
\hline \multicolumn{3}{|l|}{ Residence } \\
\hline $\operatorname{Urban}^{\dagger}$ & 1.00 & 1.00 \\
\hline Rural & $0.43(0.34-0.54)^{* *}$ & $0.81(0.59-1.11)$ \\
\hline \multicolumn{3}{|l|}{ Religion } \\
\hline Catholic $^{\dagger}$ & 1.00 & 1.00 \\
\hline Protestant & $1.17(0.96-1.41)$ & $1.05(0.85-1.29)$ \\
\hline Muslim & $1.22(0.88-1.69)$ & $0.82(0.60-1.10)$ \\
\hline Pentecostal & $1.14(0.82-1.57)$ & $0.99(0.73-1.36)$ \\
\hline Other & $1.28(0.83-1.98)$ & $1.14(0.75-1.73)$ \\
\hline \multicolumn{3}{|l|}{ Wealth status } \\
\hline Poorest $^{\dagger}$ & 1.00 & - \\
\hline Poorer & $1.31(1.02-1.68)^{*}$ & $1.10(0.84-1.44)$ \\
\hline Middle & $1.71(1.28-2.28)^{* *}$ & $1.30(0.96-1.78)$ \\
\hline Richer & $1.74(1.31-2.32)^{* *}$ & $1.18(0.86-1.63)$ \\
\hline Richest & $3.44(2.59-4.58)^{* *}$ & $1.56(1.05-2.32)^{*}$ \\
\hline \multicolumn{3}{|l|}{ Region } \\
\hline Central $^{\dagger}$ & 1.00 & 1.00 \\
\hline East & $0.63(0.48-0.82)^{* *}$ & $0.85(0.64-1.13)$ \\
\hline North & $0.35(0.26-0.48)^{* *}$ & $0.56(0.40-0.78)^{* *}$ \\
\hline South & $0.56(0.43-0.72)^{* *}$ & $0.80(0.60-1.05)$ \\
\hline \multicolumn{3}{|l|}{ Exposure to media } \\
\hline No exposure & 1.00 & 1.00 \\
\hline At least one regularly & $1.63(1.30-2.06)^{* *}$ & $1.17(0.92-1.49)$ \\
\hline \multicolumn{3}{|l|}{ Empowerment } \\
\hline Low & 1.00 & 1.00 \\
\hline Medium & $0.89(0.75-1.07)$ & $0.93(0.78-1.12)$ \\
\hline High & $1.05(0.83-1.32)$ & $1.08(0.83-1.40)$ \\
\hline \multicolumn{3}{|l|}{ Place of delivery } \\
\hline Government $^{\dagger}$ & 1.00 & 1.00 \\
\hline Private & $1.13(0.81-1.56)$ & $0.97(0.73-1.30)$ \\
\hline TBA/home & $0.59(0.48-0.74)^{* *}$ & $0.75(0.60-0.93)^{*}$ \\
\hline \multicolumn{3}{|l|}{ ANC visits } \\
\hline 4 or more ${ }^{\dagger}$ & 1.00 & 1.00 \\
\hline $1-3$ & $0.73(0.62-0.87)^{* *}$ & $0.83(0.70-0.98)^{*}$ \\
\hline None & $1.25(0.90-1.74)$ & $1.27(0.92-1.75)$ \\
\hline \multicolumn{3}{|l|}{ Breastfeeding status } \\
\hline Not breastfeeding ${ }^{\dagger}$ & 1.00 & 1.00 \\
\hline Breastfeeding & $1.00(0.84-1.19)$ & $1.10(0.92-1.32)$ \\
\hline \multicolumn{3}{|l|}{ Working status } \\
\hline Not working $^{\dagger}$ & 1.00 & 1.00 \\
\hline Working & $0.87(0.72-1.04)$ & $0.99(0.82-1.19)$ \\
\hline
\end{tabular}


TABle 4: Continued.

\begin{tabular}{|c|c|c|}
\hline \multirow{2}{*}{ Characteristics } & \multicolumn{2}{|c|}{ Hazard ratio $(95 \% \mathrm{CI})$} \\
\hline & Unadjusted & Adjusted \\
\hline \multicolumn{3}{|l|}{ Type of delivery } \\
\hline Normal $^{\dagger}$ & 1.00 & 1.00 \\
\hline Caesarean & $1.33(0.93-1.90)$ & $0.79(0.55-1.15)$ \\
\hline \multicolumn{3}{|l|}{ Birth order } \\
\hline $1 s t^{\dagger}$ & 1.00 & - \\
\hline $2-3$ & $1.07(0.81-1.41)$ & - \\
\hline $4-5$ & $0.76(0.57-1.00)$ & - \\
\hline $6++$ & $0.59(0.45-0.78)^{* *}$ & - \\
\hline \multicolumn{3}{|l|}{ Type of birth } \\
\hline Single $^{\dagger}$ & 1.00 & - \\
\hline Multiple & $0.78(0.39-1.53)$ & - \\
\hline \multicolumn{3}{|l|}{ Sex of child } \\
\hline Male $^{\dagger}$ & 1.00 & - \\
\hline Female & $1.09(0.92-1.30)$ & - \\
\hline
\end{tabular}

Note. Assessment is based on weighted data, where $n=2,889$ and $F=7.85, p<0.001$; hat-statistic $=0.992, p=0.00$; hat-square $=-.034, p=0.711$.

TABLE 5: Results of specification test of fitted model.

\begin{tabular}{lccc}
\hline Statistic & Coef. & Std. error & $p$ value \\
\hline Hat & 1.029 & 0.113 & 0.000 \\
Hat-square & -0.353 & 0.091 & 0.700 \\
\hline
\end{tabular}

surprising that unmet need for family planning has persistently remained high among poor women. The fact that the northern region is predominantly rural gives credence to the argument that the delayed adoption of modern contraception among women in the region is, among other factors, an issue of costs associated with the services.

Our findings are in agreement with studies elsewhere that have identified education as a predictor of family planning use $[20,34,45,46]$. The finding that contraceptive prevalence is higher among educated women compared with noneducated women, however, does not imply that contraceptive use increases only with education. A study by Stephenson et al. [25] on modern contraception among women in six sub-Saharan African countries revealed that postprimary education was associated with increased odds of modern contraceptive use, but the study also arrives at the same conclusion among women with primary education. This evidence implies that the minimum level of education associated with contraceptive use may vary across countries and regions.

The longer time-to-contraceptive use among women who delivered at home/TBA compared with those who delivered at public health facilities underscores the role played by health institutions in promoting family planning use in Uganda. Public and private health facilities (hospitals, health centers, and clinics) are the major sources of contraception in the country. Cleland et al. [47] suggested that all women before being discharged from the health facility should be counseled as this had a subsequent effect on contraceptive use. Successful programs have been highlighted in India that had postpartum contraception with nearly all women were satisfied with the method [16]. In light of the fact that about six in every ten women (57\%) in the country deliver at health facilities [18], there is a strong need to promote programs that target women who do not deliver at health facilities as a measure to promote contraceptive use. Examples include the Community Based Distribution (CBD) program aimed at bringing family planning services closer to the intended users, satellite clinics, and employer-based programs [44, 48, 49]. CBD is particularly important in enhancing access to reproductive health services among the rural communities.

In a recent study on family planning advice and contraceptive use, Yadav and Dhillon [26] show that use of critical maternal health services (ANC, institutional delivery, and postnatal care) encourages subsequent contraceptive use. In Tanzania, findings that showed counseling had an influence on the intention to use contraception [50]. In our study, the longer time-to-contraceptive use observed among women who attended 1-3 ANC visits compared with those who attended the recommended four or more visits supports this finding as noted elsewhere [51]. Thus, strengthening the integration of family planning into ANC services [23, 26, 52,53 ] would certainly go a long way in promoting modern contraceptive use, particularly during the postpartum period.

\section{Conclusions}

In conclusion, the findings provide evidence about the factors associated with time-to-contraceptive use after resumption of sexual intercourse following a birth. However, the findings should be interpreted in light of the following limitations, based mainly on the fact that the study used cross-sectional data: (i) all the women were not followed up for a full length of the two-year period; (ii) it is highly likely that women who used contraception after resumption of sexual intercourse were underrepresented; (iii) the analysis does not 
account for time-varying covariates such as education level and household wealth; (iv) the analysis does not account for contraceptive method mix and differentiating between limiters and spacers in contraceptive adoption. Further, the investigations were limited to women's most recent birth in the three years preceding the survey. Further investigations could explore the duration of contraceptive use and continuation in contraceptive adoption, differentiating between limiters and spacers.

\section{Abbreviations}

\section{ANC: Antenatal care}

DHS: Demographic and health survey

LAM: Lactational amenorrhea

UBOS: Uganda Bureau of Statistics

UDHS: Uganda Demographic and Health Survey

WHO: World Health Organization

UNFPA: United Nations Population Fund.

\section{Competing Interests}

The authors declare that they have no competing interests.

\section{Authors' Contributions}

Allen Kabagenyi and Robert Wamala conceptualized and designed the study. Robert Wamala led the data analysis, interpretation of findings, and writing of the manuscript. Allen Kabagenyi provided important scientific content and participated in data analysis, writing, and revisions of the manuscript. Simon Kasasa assisted in the data analysis, interpretation of findings, and discussions. All authors have read and approved the final version of the manuscript.

\section{Acknowledgments}

The authors wish to acknowledge the support from USAID through ICF International for funding this project under the 2015 DHS Fellowship Program. They are indebted to the support received from Dr. Sarah Staveteig and Dr. Wenjuan Wang, the facilitators of the workshop. Thanks are due to Ms. Kerry MacQuarrie and Dr. Shireen Assaf for reviewing this paper. They also thank the editor Bryant Robey for the valuable comments and edits.

\section{References}

[1] C. Marcolino and E. P. Galastro, "Male's and female's views on the involvement of men and women in family planning," Revista Latino-Americano de Enfermagem, vol. 9, no. 3, pp. 77-82, 2001.

[2] A. Anzaku and S. Mikah, "Postpartum resumption of sexual activity, sexual morbidity and use of modern contraceptives among Nigerian women in Jos," Annals of Medical and Health Sciences Research, vol. 4, no. 2, pp. 210-216, 2014.

[3] M. R. Borda, W. Winfrey, and C. McKaig, "Return to sexual activity and modern family planning use in the extended postpartum period: an analysis of findings from seventeen countries," African Journal of Reproductive Health, vol. 14, no. 4, pp. 72-79, 2010.

[4] S. L. Barber, "Family planning advice and postpartum contraceptive use among low-income women in Mexico," International Family Planning Perspectives, vol. 33, no. 1, pp. 6-12, 2007.

[5] T. A. Fakoya, F. A. Oluwole, O. A. Ogundahunsi et al., "Postpartum sexual abstinence and breastfeeding pattern in Sagamu, Nigeria," African Journal of Reproductive Health, vol. 12, no. 1, pp. 96-100, 2008.

[6] R. P. Ndugwa, J. Cleland, N. J. Madise, J.-C. Fotso, and E. M. Zulu, "Menstrual pattern, sexual behaviors, and contraceptive use among postpartum women in Nairobi Urban Slums," Journal of Urban Health, vol. 88, S2, pp. S341-S355, 2011.

[7] J. Bongaarts, "The proximate determinants of exceptionally high fertility," Population and Development Review, vol. 13, no. 1, pp. 133-139, 1987.

[8] J. Bongaarts and G. R. Potter, Fertility Biology and Behaviour: An Analysis of the Proximate Determinants, Academic, New York, NY, USA, 1983.

[9] P. A. Haggerty and S. O. Rutstein, Breastfeeding and Complementary Infant Feeding, and the Postpartum Effects of Breastfeeding, Macro International, Calverton, Md, USA, 1999, Demographic and Health Surveys Comparative Studies No. 30; 1999, http://www.popline.org/node/524728\#sthash.N2TjVoZX.dpuf.

[10] M. S. Ullah and N. Chakraborty, "The use of modern and traditional methods of fertility control in Bangladesh: a multivariate analysis," Contraception, vol. 50, no. 4, pp. 363-372, 1994.

[11] J. Cleland, S. Bernstein, A. Ezeh, A. Faundes, A. Glasier, and J. Innis, "Family planning: the unfinished agenda," Lancet, vol. 368, no. 9549, pp. 1810-1827, 2006.

[12] UNFPA, State of the World Population 2012; by Choice Not by Chance, Family Planning, Human Rights and Develoment, United Nations Population Fund, New York, NY, USA, 2012.

[13] M. P. Yeakey, C. J. Muntifering, D. V. Ramachandran, Y. Myint, A. A. Creanga, and A. O. Tsui, "How contraceptive use affects birth intervals: results of a literature review," Studies in Family Planning, vol. 40, no. 3, pp. 205-214, 2009.

[14] WHO, "Family planning," Fact Sheet 351, WHO Media Center, Geneva, Switzerland, 2012.

[15] T. D. Ngo, O. Nuccio, K. Reiss, and S. K. Pereira, Expanding Long-Acting and Permanent Contraceptive Use in Sub-Saharan Africa to Meet FP2020 Goals, Research, Monitoring and Evaluation Team, Health Systems Department, Marie Stopes International, London, UK, 2013.

[16] S. Kumar, R. Sethi, S. Balasubramaniam et al., "Women's experience with postpartum intrauterine contraceptive device use in India," Reproductive Health, vol. 11, article 32, 2014.

[17] A. O. Tsui, R. McDonald-Mosley, and A. E. Burke, "Family planning and the burden of unintended pregnancies," Epidemiologic Reviews, vol. 32, no. 1, pp. 152-174, 2010.

[18] Uganda Bureau of Statistics (UBOS) and ICF International Inc, Uganda Demographic and Health Survey 2011, UBOS, Kampala, Uganda; ICF International Inc.: Uganda Bureau of Statistics \& Macro International, Calverton, Md, USA, 2012.

[19] United Nations, The Millennium Development Goals Report, United Nations, New York, NY, USA, 2015.

[20] J. R. Andi, R. Wamala, B. Ocaya, and A. Kabagenyi, "Modern contraceptive use among women in Uganda: an analysis of trend and patterns (1995-2011)," African Population Studies, vol. 28, no. 2, pp. 1009-1021, 2014.

[21] K. Johnson, S. F. Posner, J. Biermann et al., "Recommendations to improve preconception health and health care-United States. A report of the CDC/ATSDR preconception care work 
group and the select panel on preconception care," Morbidity and Mortality Weekly Report, vol. 55, no. 4, pp. 1-23, 2006.

[22] J. Cleland, A. Conde-Agudelo, H. Peterson, J. Ross, and A. Tsui, "Contraception and health," The Lancet, vol. 380, no. 9837, pp. 149-156, 2012.

[23] M. Do and D. Hotchkiss, "Relationships between antenatal and postnatal care and post-partum modern contraceptive use: evidence from population surveys in Kenya and Zambia," BMC Health Services Research, vol. 13, article 6, 2013.

[24] S. Eliason, F. Baiden, G. Quansah-Asare et al., "Factors influencing the intention of women in rural Ghana to adopt postpartum family planning," Reproductive Health, vol. 10, no. 1, article 34, pp. 1-8, 2013.

[25] R. Stephenson, A. Baschieri, S. Clements, M. Hennink, and N. Madise, "Contextual influences on modern contraceptive use in sub-Saharan Africa," American Journal of Public Health, vol. 97, no. 7, pp. 1233-1240, 2007.

[26] D. Yadav and P. Dhillon, "Assessing the impact of family planning advice on unmet need and contraceptive use among currently married women in Uttar Pradesh, India," PLoS ONE, vol. 10, no. 3, Article ID e0118584, 2015.

[27] A. Kabagenyi, P. Ndugga, S. O. Wandera, and B. Kwagala, "Modern contraceptive use among sexually active men in Uganda: does discussion with a health worker matter?" BMC Public Health, vol. 14, no. 1, article no. 286, 2014.

[28] K. I. Kennedy, R. Rivera, and A. S. McNeilly, "Consensus statement on the use of breastfeeding as a family planning method," Contraception, vol. 39, no. 5, pp. 477-496, 1989.

[29] T. Lutalo, G. Kigozi, E. Kimera et al., "A randomized community trial of enhanced family planning outreach in Rakai, Uganda," Studies in Family Planning, vol. 41, no. 1, pp. 55-60, 2010.

[30] Family Health Initiative, Expanding Contraceptive Use in Urban Uttar Pradesh: Family Planning: Effect of Data Driven Strategies. Policy Brief, 2010.

[31] S. E. Neal, V. Chandra-Mouli, and D. Chou, "Adolescent first births in East Africa: disaggregating characteristics, trends and determinants Adolescent Health," Reproductive Health, vol. 12, article 13, 2015.

[32] S. O. Gyimah, J. K. Adjei, and B. K. Takyi, "Religion, contraception, and method choice of married women in Ghana," Journal of Religion and Health, vol. 51, no. 4, pp. 1359-1374, 2012.

[33] P. K. Kayembe, A. B. Fatuma, M. A. Mapatano, and T. Mambu, "Prevalence and determinants of the use of modern contraceptive methods in Kinshasa, Democratic Republic of Congo," Contraception, vol. 74, no. 5, pp. 400-406, 2006.

[34] O. Kravdal, "A search for aggregate-level effects of education on fertility, using data from Zimbabwe," Demographic Research, vol. 3, article no. 3, 2000.

[35] A. A. Creanga, D. Gillespie, S. Karklins, and A. O. Tsui, "Low use of contraception among poor women in Africa: an equity issue," Bulletin of the World Health Organization, vol. 89, no. 4, pp. 258-266, 2011.

[36] R. M. Andersen, "Revisiting the behavioral model and access to medical care: does it matter?" Journal of Health and Social Behavior, vol. 36, no. 1, pp. 1-10, 1995.

[37] J. A. Ross and W. L. Winfrey, "Contraceptive use, intention to use and unmet need during the extended postpartum period," International Family Planning Perspectives, vol. 27, no. 1, pp. 20 27, 2001.

[38] A. Kabagenyi, L. Jennings, A. Reid, G. Nalwadda, J. Ntozi, and L. Atuyambe, "Barriers to male involvement in contraceptive uptake and reproductive health services: a qualitative study of men and women's perceptions in two rural districts in Uganda," Reproductive Health, vol. 11, no. 1, article no. 21, 2014.
[39] S. Bradley, T. N. Croft, J. D. Fishel, and C. F. Westoff, "Revising unmet need for family planning," in DHS Analytical Studies No 25, USA Demographic and Health Research Division, ICF International, Calverton, Md, USA, 2012.

[40] J. Hopkins, Family Planning: A Global Handbook for Providers. 2011 Update, WHO, 2011.

[41] D. A. Belsley, E. Kuh, and R. E. Welsch, Recession Diagnostics, John Wiley and Sons, New York, NY, USA, 1980.

[42] United Nations DoEaSA Population Division, World Fertility Data 2008 (POP/DB/Fert/Rev2008), Department of Economic and Social Affairs, Population Division, 2009.

[43] United Nations Department of Economic and Social Affairs PD, World Population Prospects: The 2012 Revision, File POP/1-1: Total Population (Both Sexes Combined) by Major Area, Region and Country, Annually for 1950-2100, POP/DB/WPP/Rev2012/ POP/F01-1, United Nations, 2013.

[44] O. Nakayiza, R. Wamala, and B. Kwagala, "Determinants of preference of source of injectable contraceptives among rural women in Uganda: a case study of Depo-Provera," African Journal of Reproductive Health, vol. 18, no. 3, pp. 48-56, 2014.

[45] C. B. Polis, R. H. Gray, T. Lutalo et al., "Trends and correlates of hormonal contraceptive use among HIV-infected women in Rakai, Uganda, 1994-2006," Contraception, vol. 83, no. 6, pp. 549-555, 2011.

[46] A. Al Riyami, M. Afifi, and R. M. Mabry, "Women's autonomy, education and employment in Oman and their influence on contraceptive use," Reproductive Health Matters, vol. 12, no. 23, pp. 144-154, 2004.

[47] J. Cleland, I. H. Shah, and M. Daniele, "Interventions to improve postpartum family planning in low- and middle-income countries: program implications and research priorities," Studies in Family Planning, vol. 46, no. 4, pp. 423-441, 2015.

[48] J. Stanback, A. K. Mbonye, and M. Bekiita, "Contraceptive injections by community health workers in Uganda: a nonrandomized community trial," Bulletin of the World Health Organization, vol. 85, no. 10, pp. 768-773, 2007.

[49] S. Malarcher, O. Meirik, E. Lebetkin, I. Shah, J. Spieler, and J. Stanback, "Provision of DMPA by community health workers: what the evidence shows," Contraception, vol. 83, no. 6, pp. 495$503,2011$.

[50] S. C. Keogh, M. Urassa, Y. Kumogola, S. Kalongoji, D. Kimaro, and B. Zaba, "Postpartum contraception in Northern Tanzania: patterns of use, relationship to antenatal intentions, and impact of antenatal counseling," Studies in Family Planning, vol. 46, no. 4, pp. 405-422, 2015.

[51] O. Pasha, S. S. Goudar, A. Patel et al., "Postpartum contraceptive use and unmet need for family planning in five low-income countries," Reproductive Health, vol. 12, no. 2, article no. S11, 2015.

[52] H. Birungi and W. Onyango-Ouma, "Acceptability and sustainability of the WHO focused antenatal care package in Kenya," in Frontiers in Reproductive Health, Population Council, Washington, DC, USA, 2006.

[53] G. Rutaremwa, A. Kabagenyi, S. O. Wandera, T. Jhamba, E. Akiror, and H. L. Nviiri, "Predictors of modern contraceptive use during the postpartum period among women in Uganda: a population-based cross sectional study Health behavior, health promotion and society," BMC Public Health, vol. 15, article 262, 2015. 


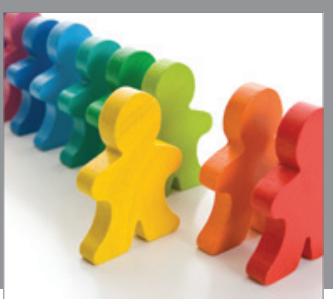

Autism

Research and Treatment
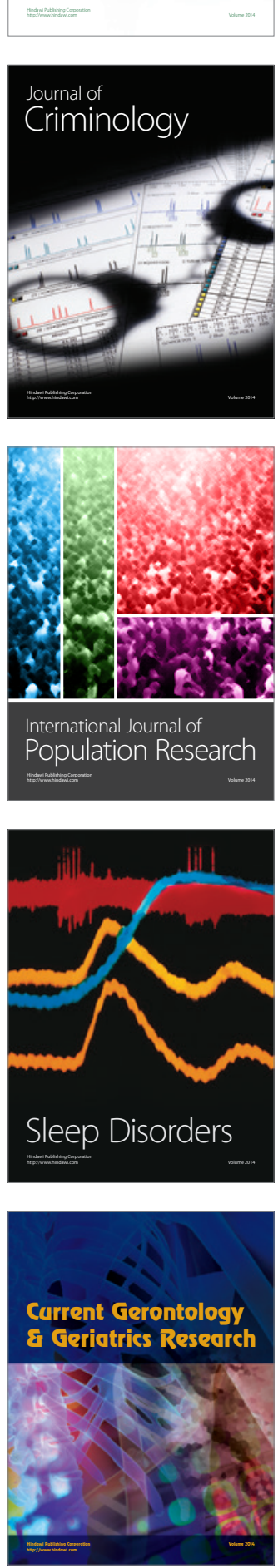

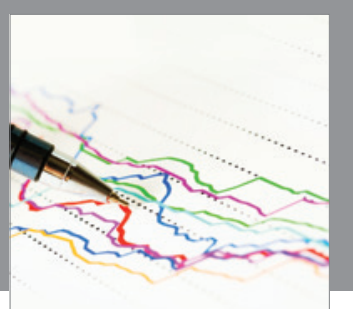

Economics

Research International
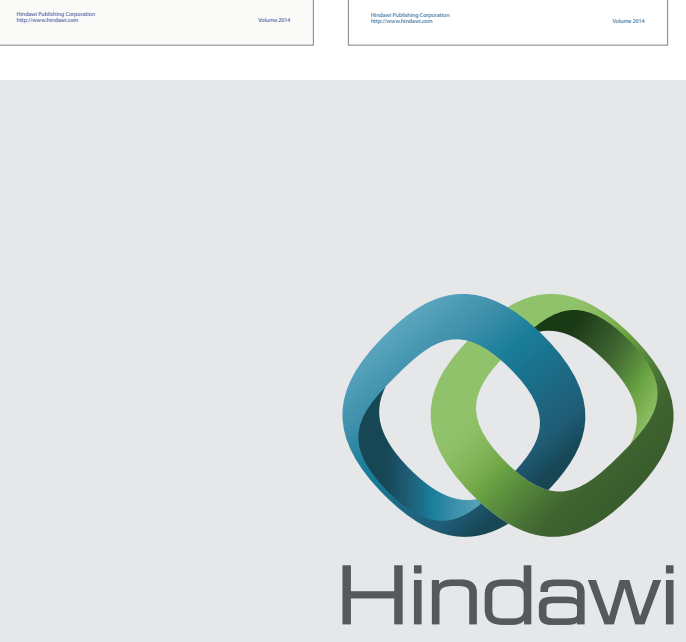

Submit your manuscripts at

https://www.hindawi.com
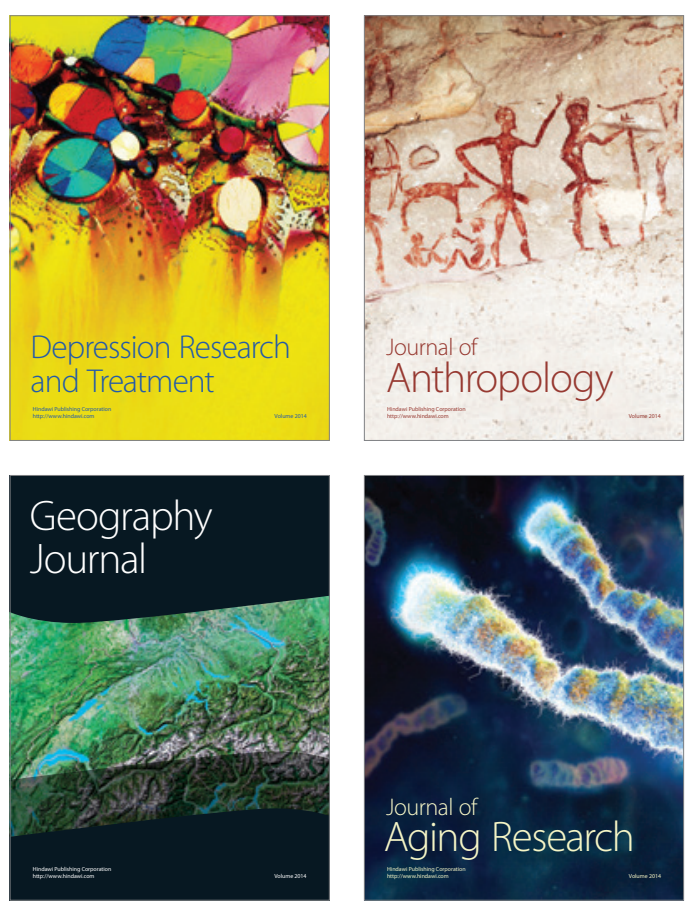
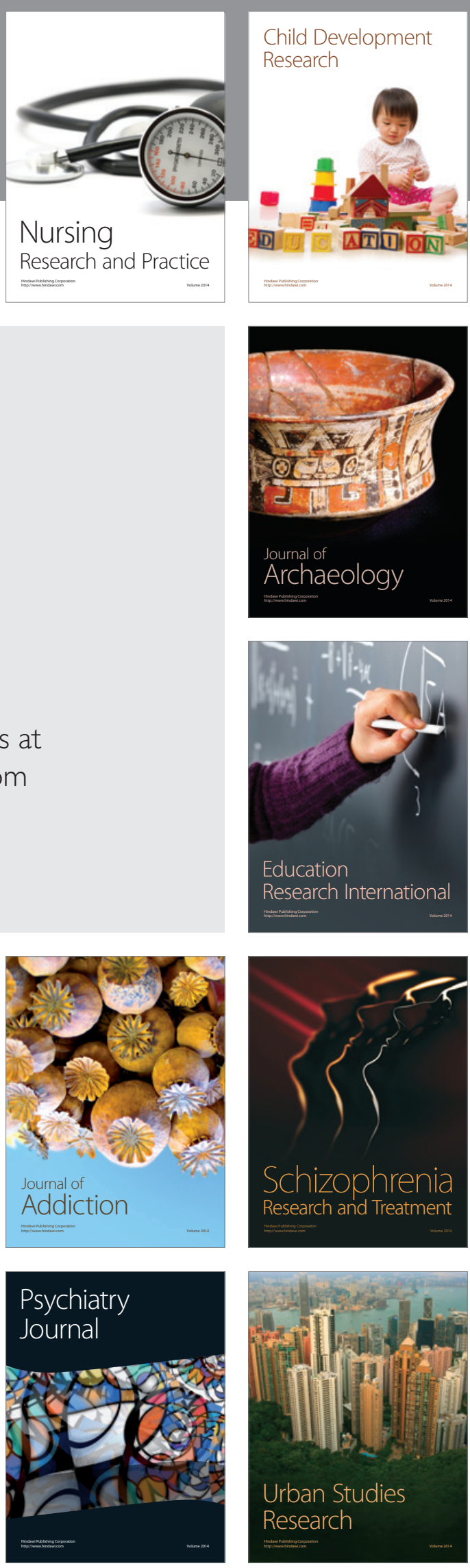